\section{The effects of luteolin on phenoloxidase and the growth of Spodoptera exigua (Hübner) larvae (Lepidoptera: Noctuidae)}

\author{
Shu-Dong Wang, Wei Liu, Chao-Bin Xue and \\ Wan-Chun Luo* \\ College of Plant Protection, Key Laboratory of Pesticide Toxicology \\ and Application Technique, Shandong Agricultural University, \\ Taiwan 271018, P. R. China
}

(Received March 17, 2010; Accepted July 10, 2010)

The effects of luteolin on phenoloxidase (PO) from Spodoptera exigua larvae were investigated with the use of a microtitration assay in the present paper. The results showed that luteolin could inhibit the activity of PO and the concentration of this inhibitor that led to a $50 \%\left(\mathrm{IC}_{50}\right)$ activity reduction was estimated to be $0.47 \mathrm{mmol} / 1$. The inhibitory kinetics were analyzed by LineweaverBurk plots and the compound was found to be a reversible competitive inhibitor with a $K_{\mathrm{i}}$ of $13.11 \mathrm{mmol} / 1$. The compound was obviously toxic against the larvae ( $\leq 3 \mathrm{rd}$ instar) of Spodoptera exigua. The highest inhibitory percentage in the older larvae $(\geq 3 \mathrm{rd}$ instar) was greater than $60 \%$ with luteolin treatment. The pupation rate and percentage of eclosion was also evidently reduced with luteolin treatment by the ingestion method in this investigation. (C) Pesticide Science Society of Japan

Keywords: luteolin, Spodoptera exigua, phenoloxidase, inhibition kinetics.

\section{Introduction}

Flavonoids, which are a specific type of phenolic compound, are distributed extensively throughout the plant kingdom. The basic chemical structure of the flavonoids contain 15 carbon atoms that comprise two aromatic rings combined with three carbon atoms in addition to $O$-alkyl and its secondary consubstituents. Luteolin (2-(3,4-dihydroxyphenyl)-5,7-dihydroxy-4-chromenone) is a representative and naturally occurring flavone that belongs to a subgroup of tetrahydroxy flavonoids. ${ }^{1)}$ Luteolin has been extensively investigated and studies have indicated that this compound has some medical efficacy as an expectorant and cough suppressant, as well as exhibiting anti-inflammatory effects in clinical applica-

\footnotetext{
* To whom correspondence should be addressed.

E-mail:wcluo@sdau.edu.cn

Published online September 6, 2010

(C) Pesticide Science Society of Japan
}

tions. ${ }^{2-5)}$ However, the effects of luteolin on insects have not been reported to date.

Phenoloxidase (PO, EC.1.14.18.1), which is also known as tyrosinase, plays an important role in various developmental processes of insects, ${ }^{6-8)}$ such as cuticular tanning, scleration, wound healing, and the formation of nodules that defend the insect from foreign pathogens. It is logical to regard PO as a target for new insecticides with novel modes of action. ${ }^{5-6)}$ Therefore, the effect and mechanism of luteolin on PO activity in Spodoptera exigua larvae using L-DOPA ((2S)-2-amino-3-(3,4dihydroxyphenyl) propanoic acid) as a substrate were investigated. The mode of action of luteolin and the intensity of its effects on the test larvae were also assessed in this paper.

\section{Materials and Methods}

\section{Insects}

The larvae of Spodoptera exigua (Hübner) were reared and gathered for the experiment. ${ }^{9)}$

\section{Enzyme purification}

The 5th instar tested larvae were homogenized in a 5-fold weight of ice-cold $0.02 \mathrm{mmol} / 1$ sodium phosphate buffer ( $\mathrm{pH} 6.50)$. The homogenate was filtered through gauze and centrifuged at 8000 $\mathrm{rpm}$ (CR22, Japan) for $30 \mathrm{~min}$ at $4^{\circ} \mathrm{C}$. The supernatant under the fat layer was collected as the crude enzyme extract, and this was brought to a saturation of $40 \%$ with solid ammonium sulfate and chilled in an ice-bath for $20 \mathrm{~min}$. The resulting precipitate was collected by centrifugation at $8000 \mathrm{rpm}$ for $30 \mathrm{~min}$ at $4^{\circ} \mathrm{C}$ and dialyzed against the same phosphate buffer until the sulfate ions were not detected. The dialyzed solution was gel-filtered through a Sephadex G-100 column that was equilibrated with the same buffer. The fractions with high enzymatic activities were collected and used as partially purified PO. ${ }^{10)}$

\section{Enzyme assays}

PO catalyzes the reaction between a phenolic compound and oxygen. This report assayed the activity of PO in air-saturated solutions so that the oxygen content was not a limiting factor. The enzymatic activity of PO was assayed with the microtitration assay method. ${ }^{11)}$ A $200 \mu$ l aliquot of the sample, which included the final concentration of $0.10 \mathrm{mmol} / 1$ phosphate buffer $(\mathrm{pH}$ 6.50) and $1.00 \mathrm{mmol} / 1 \mathrm{~L}-\mathrm{DOPA}$, was incubated at $30^{\circ} \mathrm{C}$ for $10 \mathrm{~min}$. Then $10 \mu \mathrm{l}$ of the aqueous PO solution was added and the linear increase was measured immediately with a microplate reader (Multiskan MK3) at a wavelength of $400 \mathrm{~nm}$. One unit (U) of PO activity was expressed as a 0.001 change in absorbance per min per mg protein.

\section{Effect of luteolin on $P O$}

To examine the effect of luteolin on PO in vitro, the phenolase assay system was used as above but with different concentrations of luteolin dissolved firstly in a small amount of dimethyl sulfox- 
ide (DMSO). The relative enzyme activity was calculated and compared to normal control larvae. The extent of inhibition was expressed as the percentage necessary to inhibit $50 \%$ of PO activity $\left(\mathrm{IC}_{50}\right)$.

\section{The type and constant of inhibition of PO activity by lute- olin}

For kinetic analyses, the inhibitor concentration was held fixed and the substrate concentrations were varied in the enzyme assay system for the determination of the initial reaction rate. The inhibition type was analyzed by Lineweaver-Burk plots, and the inhibition constant was determined by plotting the apparent Michaelis-Menten constant versus the inhibitor concentration.

\section{Determination of feeding toxicity}

To explore the effect of luteolin on PO in vivo, flakes of an artificial diet were dipped into a series of concentrations of luteolin solution for $20 \mathrm{~s}$ and then placed in larva-rearing tubes after the excess liquid was absorbed using absorbent paper. Acetone was used as the control. The larvae ( $\leq 3 \mathrm{rd}$ instar) were placed in larvae-rearing tubes with diets containing luteolin at various concentrations. Each replication had 20 larvae and three replications formed one treatment. $48 \mathrm{~h}$ later, the activities of PO were measured. The insect mortality was recorded until the tested larvae began to pupate in the control group. The virulence regression equation and the $\mathrm{LC}_{50}$ were calculated through statistical analysis by DPS software.

\section{Effect of luteolin on the growth and development of Spodoptera exigua}

The 3rd instar larvae of Spodoptera exigua were pre-weighed and placed into larvae-rearing tubes with diets that contained different concentrations of luteolin. The insects were weighed again at $24 \mathrm{~h}$ and $48 \mathrm{~h}$ after treatment to calculate the inhibition percentage, and observation of the larvae continued in order to calculate the pupation and eclosion rates.

$$
\begin{aligned}
\text { Inhibition rates }(\%)= & {[(\text { weight gain in the control group }} \\
& - \text { weight gain in the treated group }) \\
& /(\text { weight gain in the treated group })] \times 100
\end{aligned}
$$

\section{Results}

\section{Effect of luteolin on phenoloxidase}

The relationship between the relative enzymatic activity and the concentrations of luteolin is shown in Fig. 1. The relative enzymatic activity decreased in proportion with increasing concentrations of the inhibitor. At an inhibitor concentration of 0.15 $\mathrm{mmol} / \mathrm{l}$, the activity of the enzyme was $67.21 \%$ of the maximum, while at an inhibitor concentration of $0.45 \mathrm{mmol} / \mathrm{l}$, the remaining activity decreased to $45.34 \%$. The $\mathrm{IC}_{50}$ of luteolin for Spodoptera exigua $\mathrm{PO}$ activity was estimated to be $0.47 \mathrm{mmol} / \mathrm{l}$.

The relationship between PO activity and enzyme concentrations in the presence of different inhibitor concentrations was also studied (Fig. 2), yielding straight lines that passed through the origin, and higher inhibitor concentrations were associated

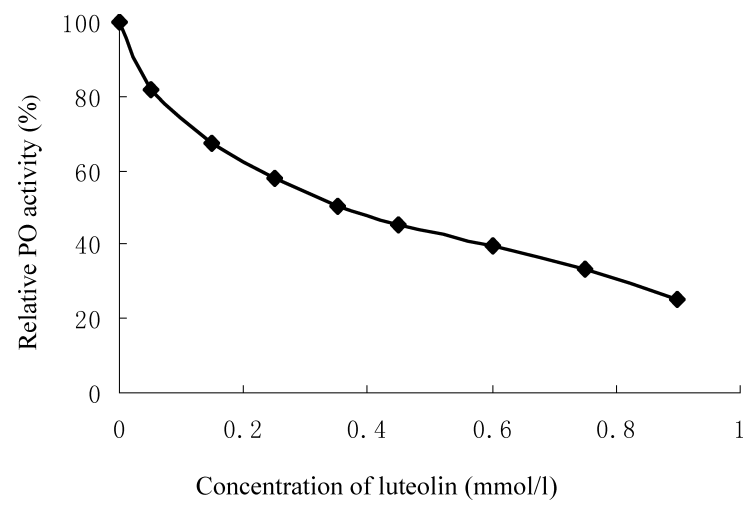

Fig. 1. The effect of luteolin on phenoloxidase in vitro.

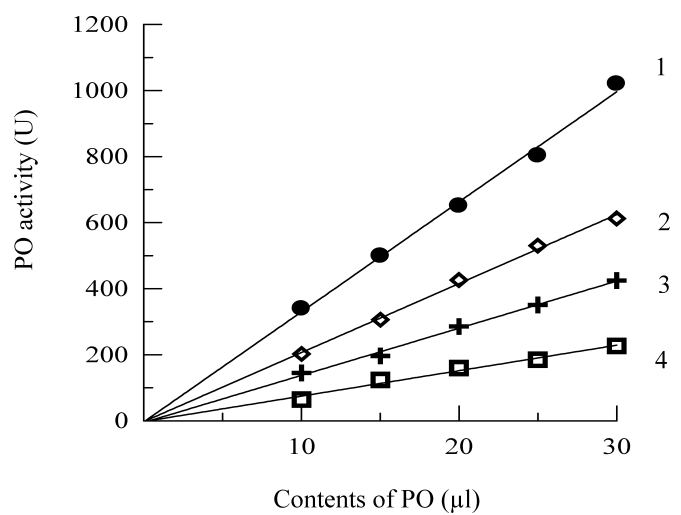

Fig. 2. The effect of different concentrations of luteolin on the activity of PO.

with decreased gradients of the slopes, demonstrating that the inhibition of PO by luteolin was reversible.

The effect of luteolin on PO in vivo was assayed (Fig. 3). With increasing concentrations of inhibitor, the relative enzymatic activity decreased, indicating that luteolin inhibits the activity of PO in Spodoptera exigua larvae.

\section{Determination of type and constant of inhibition of $P O$} activity by luteolin

The kinetic behavior of PO was studied in terms of its oxidation

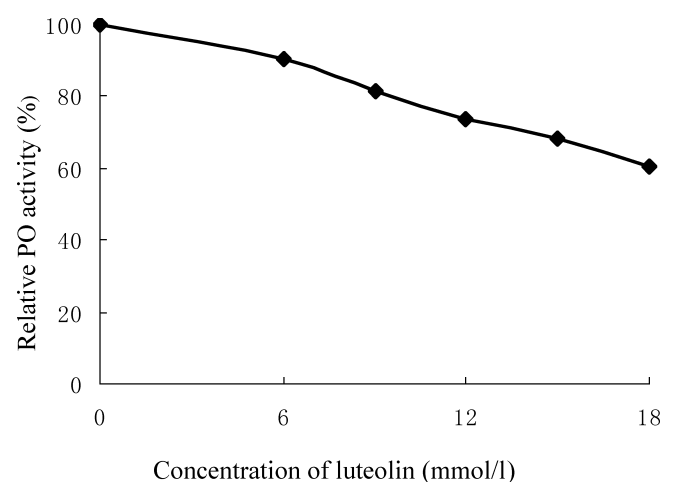

Fig. 3. The effect of luteolin on $\mathrm{PO}$ in vivo. 


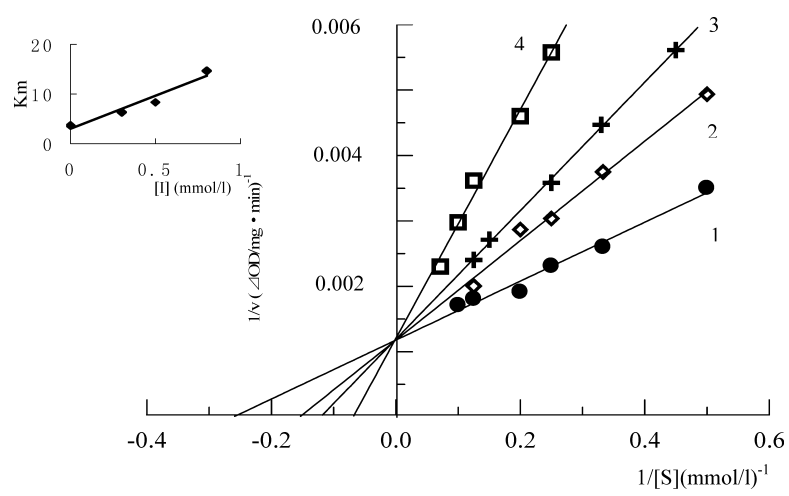

Fig. 4. Lineweaver-Burk plots for the inhibition of PO activity by luteolin. The concentrations of luteolin for lines $1-4$ were $0,0.30$, $0.50,0.80 \mathrm{mmol} / 1$, respectively.

of L-DOPA, which was shown to follow Michaelis-Menten kinetics (Fig. 4). The assay was carried out in air-saturated aqueous solutions as indicated above, so the $K_{m}$ and $V_{m}$ values obtained did not take the effect of oxygen concentration into account. In this system, increasing the inhibitor concentration yielded data lines with common intercepts on the $1 / v$ axis but with different slopes, which indicated that the inhibitor did not change the apparent maximum velocity $\left(V_{\text {mapp }}\right)$ of the PO activity but did change the apparent Michaelis-Menten constant $\left(K_{\text {mapp }}\right)$. These results indicate that luteolin is a competitive inhibitor. As changes in the luteolin concentration did not alter the $V_{\text {mapp }}$ and increasing substrate concentrations decreased the inhibitory effect, it is likely that the inhibitor and the enzyme competed for the substrate. The increase in $K_{\text {mapp }}$ with increased inhibitor concentration demonstrated that the affinity of PO for its substrate was weakened, and luteolin could affect the interaction between the enzyme and the substrate. The linear plot of $K_{\text {mapp }}$ versus the concentration of luteolin (Fig. 4 inset) was used to estimate the equilibrium constant for inhibitor binding to the free enzyme $\left(K_{\mathrm{i}}\right)$, which was estimated to be $13.11 \mathrm{mmol} / \mathrm{l}$.

\section{Determination of feeding toxicity}

The insect mortality and the toxicity analysis were recorded as shown as in Table 1 and Table 2. The results indicate that luteolin could possess toxicity to the larvae ( $\leq 3 \mathrm{rd}$ instar). The higher mortality of test larvae given with the same concentration of luteolin was associated with a longer period of treatment. The mortality of test larvae given an luteolin concentration of $2 \mathrm{~g} / 1$ were $15.76 \%, 26.29 \%, 33.75 \%$ and $42.64 \%$ at $5 \mathrm{~d}, 7 \mathrm{~d}, 9 \mathrm{~d}$ and $11 \mathrm{~d}$, respectively. Meanwhile, the higher mortality was also related with higher concentrations of luteolin. At day 11, the mortality of test larvae given luteolin concentrations of $4 \mathrm{~g} / 1,8 \mathrm{~g} / 1$ and $16 \mathrm{~g} / \mathrm{l}$ was $61.04 \%, 77.65 \%$ and $90.48 \%$, respectively (Table 1 ).

\section{Effect of luteolin on the growth and development of Spodoptera exigua}

The results showed that luteolin could inhibit the growth and development of the larvae (3rd instar). The inhibitory effect increased with increasing concentrations of luteolin: at $48 \mathrm{~h}$, the inhibitions of weight gain from the tests were $49.63 \%$ and $56.28 \%$ after luteolin concentrations of $4 \mathrm{~g} / 1$ and $8 \mathrm{~g} / 1$ were given, respectively (Table 3).

Luteolin had an inhibitory effect on the pupation or eclosion of the insect larvae (Table 4). In the treatment groups, the rates of both pupation and eclosion were evidently decreased compared with the control group. Luteolin at higher concentrations could

Table 1. Bioactivities of luteolin on the larvae of Spodoptera exigua ( $\leq 3 \mathrm{rd}$ instar)*

\begin{tabular}{cccccc}
\hline \multirow{2}{*}{$\begin{array}{c}\text { Concentration of } \\
\text { luteolin }(\mathrm{g} / \mathrm{l})\end{array}$} & \multicolumn{5}{c}{ Mortality (\%) } \\
\cline { 2 - 6 } & $3 \mathrm{~d}$ & $5 \mathrm{~d}$ & $7 \mathrm{~d}$ & $9 \mathrm{~d}$ & $11 \mathrm{~d}$ \\
\hline 2 & $10.07 \pm 0.56$ & $15.76 \pm 2.78$ & $26.29 \pm 1.94$ & $33.75 \pm 3.45$ & $42.64 \pm 2.51$ \\
4 & $23.47 \pm 2.33$ & $37.95 \pm 0.63$ & $48.48 \pm 0.87$ & $57.37 \pm 2.19$ & $61.04 \pm 3.14$ \\
8 & $29.76 \pm 0.15$ & $47.27 \pm 4.81$ & $57.73 \pm 4.58$ & $72.90 \pm 2.29$ & $77.65 \pm 3.62$ \\
16 & $33.23 \pm 1.12$ & $60.61 \pm 2.59$ & $74.47 \pm 3.12$ & $84.13 \pm 3.52$ & $90.48 \pm 2.40$ \\
\hline
\end{tabular}

* The mortality was an adjusted value.

Table 2. Toxicity of luteolin against the larvae of Spodoptera exigua ( $\leq 3 \mathrm{rd}$ instar)

\begin{tabular}{cccc}
\hline $\begin{array}{c}\text { Treatment time } \\
\text { days }\end{array}$ & $\begin{array}{c}\text { Virulence regression equation } \\
\text { LD-P line }(y=\mathrm{a}+\mathrm{b} x)\end{array}$ & $\begin{array}{c}\mathrm{LC}_{50} \\
\mathrm{~g} / \mathrm{l}\end{array}$ & $\begin{array}{c}95 \% \text { confidence } \\
\text { intervals }\end{array}$ \\
\hline 5 & $y=3.5681+1.5029 x$ & 8.97 & $6.88-11.69$ \\
7 & $y=3.8169+1.5875 x$ & 5.56 & $4.55-6.79$ \\
11 & $y=4.1040+1.6323 x$ & 3.54 & $3.21-3.90$ \\
& $y=4.3651+1.5771 x$ & 2.53 & $2.37-2.70$ \\
\hline
\end{tabular}


Table 3. The effect of luteolin on the body weight of larvae of Spodoptera exigua (3rd instar)*

\begin{tabular}{|c|c|c|c|c|}
\hline \multirow{2}{*}{$\begin{array}{l}\text { Concentration of } \\
\text { luteolin } g / 1\end{array}$} & \multicolumn{2}{|c|}{ Body weight (g/larva) } & \multirow{2}{*}{$\begin{array}{c}\text { Increase in } \\
\text { weight }\end{array}$} & \multirow{2}{*}{$\begin{array}{c}\text { Percentage of inhibited } \\
\text { weight gain }(\%)\end{array}$} \\
\hline & $24 \mathrm{~h}$ & $48 \mathrm{~h}$ & & \\
\hline 1 & $0.0699 \pm 0.05$ & $0.1140 \pm 0.01$ & 0.0441 & 37.96 \\
\hline 2 & $0.0680 \pm 0.01$ & $0.1088 \pm 0.02$ & 0.0408 & 42.68 \\
\hline 4 & $0.0659 \pm 0.01$ & $0.1017 \pm 0.00$ & 0.0358 & 49.63 \\
\hline 8 & $0.0658 \pm 0.03$ & $0.0966 \pm 0.00$ & 0.0307 & 56.82 \\
\hline 16 & $0.0693 \pm 0.06$ & $0.0929 \pm 0.01$ & 0.0236 & 66.85 \\
\hline Control (acetone) & $0.0767 \pm 0.01$ & $0.1478 \pm 0.01$ & 0.0711 & - \\
\hline
\end{tabular}

* All data are presented as mean averages.

Table 4. The effect of luteolin on the pupation and eclosion of Spodoptera exigua pupa**

\begin{tabular}{cccc}
\hline $\begin{array}{c}\text { Concentration of } \\
\text { luteolin }(\mathrm{g} / \mathrm{l})\end{array}$ & $\begin{array}{c}\text { Pupa weight } \\
(\mathrm{g} / \text { pupae })\end{array}$ & $\begin{array}{c}\text { Pupation } \\
(\%)\end{array}$ & $\begin{array}{c}\text { Eclosion } \\
(\%)\end{array}$ \\
\hline 0.1 & $0.0905 \pm 0.02$ & $96.67 \pm 0.52$ & $86.67 \pm 2.71$ \\
0.2 & $0.0898 \pm 0.03$ & $90.00 \pm 0.00$ & $83.33 \pm 2.71$ \\
0.4 & $0.0798 \pm 0.05$ & $70.00 \pm 3.66$ & $66.67 \pm 2.01$ \\
0.8 & $0.0743 \pm 0.06$ & $53.33 \pm 1.92$ & $43.33 \pm 1.92$ \\
1.6 & $0.0647 \pm 0.02$ & $36.67 \pm 2.01$ & $36.67 \pm 2.01$ \\
Control (acetone) & $0.1054 \pm 0.01$ & $96.67 \pm 1.40$ & $96.67 \pm 1.40$ \\
\hline
\end{tabular}

* All data are averaged.

also significantly affect the pupal weight. The average pupal weights after luteolin concentrations of $0.4 \mathrm{~g} / 1$ and $0.8 \mathrm{~g} / 1$ were given were $0.0798 \mathrm{~g}$ and $0.0743 \mathrm{~g}$ per pupa, which were lower values than the $0.1054 \mathrm{~g}$ weight gain per pupa found in the control group (Table 4).

\section{Discussion}

The inhibition of flavonoids by a number of enzymes is based on the reaction of polyphenols with proteins. Flavonoids belong to the family of polyphenolic compounds and contain some phenolic hydroxyl groups. ${ }^{12)}$ Judging from its molecular structure, luteolin can easily oxidize $o$-phenolic hydroxyl in the same manner as the $o$-phenolic hydroxyl of the substrate L-DOPA. The inhibition of PO by luteolin was reversible and competitive, which is likely to be related to the structural homology between the inhibitor and the substrate.

PO is comprised of several subunits, and each of these contains two binuclear copper ions. Each copper ion combines with two smooth and one straight histidine ligand, and one $\mathrm{O}-\mathrm{O}$ bond unites the two copper ions at each active site. ${ }^{13)}$ The luteolin $o$ phenolic hydroxyl can form a stable complex with copper, iron, and other metal ions, through its oxygen anion. ${ }^{14)}$ Siegbabn found that phenols substrates could bind the active site copper ion noncovalently in the oxidation reaction cycle catalysed by PO, which is then oxidized to generate quinones through transferring electrons from the substrate to the copper center that is bound by the O-O bond. ${ }^{15)}$

Cyclic voltammetry and in situ UV-Vis spectroelectrochemical methods were used to investigate the electro-oxidation processes of luteolin. The results showed that $o$-quinones from $3^{\prime}, 4^{\prime}$-o-dihydroxy are the stable oxidation products of the activity of PO. ${ }^{14)}$ The inhibition of PO by luteolin was reversible and competitive, which may indicate that the inhibitor and the substrate compete against each other to react with the copper molecules at the active site of the enzyme. However, the full elucidation of this interaction awaits further work.

Inhibition of PO activity can disturb the growth of an insect, which is one of the potential biological ways to develop a novel candidate insecticide. ${ }^{16)}$ This study indicated that luteolin has a negative impact on PO activity and the growth or development of Spodoptera exigua larvae.

\section{Acknowledgements}

This work was supported by Grants from the Expert National Ministry of Education Foundation of China (no. 20070434006) to WanChun Luo; Postdoctoral Innovation Foundation of Shandong Province (no. 200902009) and Foundation for Postdoctor of Shandong Agricultural University (no. 200976261) to Chao-Bin Xue.

\section{References}

1) S. Y. Jeong, H. S. Sang, H. P. Jong and C. K. Young: Arch. Pharm. Res. 27, 589-592 (2004).

2) K. Horvathova, I. Chalupa and L. Sebova: Mutation Reserch. 565, 105-112 (2005).

3) A. García-Lafuente, E. Guillamón, A. Villares, M. A. Rostagno and J. A. Martínez: Inflammation Res. 58, 537-55 (2009).

4) F. F. Zhang, H. M. Shen and X. Q. Zhu: J. Zhenjiang Univer. (Med. Sci.) 35, 573-578 (2006) (in Chinese).

5) J. Y. Ying, S. J. Gu and T. W. Yao: Acta. Pharm. Sinica 43, 335-342 (2008).

6) M. Lokstan (eds.): "Insect Biochemistry," Science Press, Beijing. pp. 151-153, 1988 .

7) M. Ashid and H. I. Yamazaki (eds.): "Molting and Metamorphosis,” Japanese Science Society Press, Tokyo, pp. 239-265, 
1990.

8) R. C. Micheal, R. Kiran and B. James: Insect Biochem. Molec. Biol. 30, 953-967 (2000).

9) W. Mu, K. M. Wu and G. M. Liang: Chinese J. Pesitic. Sci. 3, 93-96 (2002) (in Chinese).

10) X. X. Gao, W. C. Luo, G. Y. Xie, C. B. Xue and Q. Ding: Scientia Agricultura Sinica. 37, 687-691 (2004) (in Chinese).

11) T. Xiao, S. Z. Liu and C. B. Xue: Chinese Bull. Entomol. (in Chinese) 45, 306-309 (2008).
12) S. M. Wang: Strait Pharm. J. 16, 10-13 (2004) (in Chinese).

13) I. Kubo, K. Swapan and I. Kinst-Hori: Bioorg. Med. Chem. Lett. 4, 1443-1446 (1994).

14) J. B. He, J. Q. Du, S. J. Yuan, F. Qi and F. S. Meng: Food Science 30, 37-40 (2009).

15) P. E. M. Siegbabn: J. Biol. Inorg. Chem. 8, 567-576 (2003).

16) C. B. Xue, L.Zhang and W. C. Luo: Bioorg. Med. Chem. 15, 2006-2015 (2007). 